\title{
The 2012 International Vocabulary of Metrology: "VIM"
}

\author{
Paul De Bièvre
}

Published online: 9 March 2012

(C) Springer-Verlag 2012

One of the most important events in the last decade for the future of measurement is without any doubt the third edition of the International Vocabulary of Metrology, commonly called "VIM" (from the French title "Vocabulaire International de Métrologie") [1]. It was developed in Working Group 2 (WG 2) of the Joint Committee for Guides on Metrology (JCGM) that consists of:

- BIPM, International Bureau for Weights and Measures,

- IEC, International Electrotechnical Committee,

- IFCC, International Federation for Clinical Chemistry and Laboratory Medicine,

- ILAC, International Laboratory Accreditation Cooperation,

- ISO, International Organization for Standardization,

- IUPAC, International Union for Pure and Applied Chemistry,

- IUPAP, International Union for Pure and Applied Physics,

- OIML, International Organization for Legal Metrology.

The formal structure of the membership was intended to guarantee that the resulting "Guides for Metrology" VIM and GUM (guide to the expression of uncertainty in measurement) [2] would be formally examined, approved, and formally backed up by international organizations and therefore be internationally representative. It was also expected that the presence of international professional

The author is a member of the Joint Committee on Guides for Metrology (JCGM), Working Group 2 (VIM). The opinions expressed in this column do not necessarily represent the view of the Working Group.

P. De Bièvre $(\square)$

Kasterlee, Belgium

e-mail: paul.de.bievre@skynet.be associations such as IEC, IFCC, IUPAC, and IUPAP would promote its implementation on the worldwide scene.

The first VIM sometimes called "VIM 1," was released in 1984 [3]. The second edition, sometimes called "VIM 2," was published in 1993/1995 [4]. The VIM that is now available is the third version, called "VIM 3". It was released in 2008 and has been re-issued with editorial corrections on 16 February 2012 [1].

VIM 1 and VIM 2 were mainly conceived by physicists and engineers for measurements in physics and engineering. Chemical measurement was considered to some degree in VIM 2, thanks to the presence of an IFCC representative and by the fact that clinical chemistry-possibly through its active Clinical Chemistry Division in the IUPAC—had already made considerable progress in the introduction of metrological principles in clinical measurement. In general, the growth of more metrological insight in "measurement" in chemistry evolved considerably in the period 1970-2010 and is still in full development [5].

A first feature of VIM 3 is the change of title: "International Vocabulary of Metrology-Basic and general concepts and associated terms" whereas the title of VIM 1 and VIM 2 was very different: "International vocabulary of basic and general terms in metrology" (emphasis by me). Stressing that concepts are to be defined, and not terms, is one of the basic clarifications by VIM 3. Without commonly defined concepts, there is no possibility of validly translating the term associated with this concept from one language into a similarly understood term in another language. That had to be a justification in its own right for any successor of VIM 2. Introducing this in VIM 3 required considerable study and discussions.

A second feature of VIM 3 is the concept "measurement uncertainty" (entry 2.26 in [1]) [2]. That change of thinking was formally initiated by the International Committee 
on Weights and Measures (known in the French language as "Comité International des Poids et Mesures," CIPM) in 1981 [6]. This change has been addressed elsewhere [7] and will not be further elaborated here. Be it sufficient to note that new concepts used in the GUM were included in the VIM and sometimes vice versa. The aim is to achieve full consistency between VIM and GUM in the future.

A third feature of VIM 3 is the need to cover chemical (including bio-chemical) measurement. That was very much needed because of the explosive development of analytical chemical measurement in the last decades, caused by its application in international trade and commerce, its use in monitoring environmental and food pollution as well as in medical diagnosis of patients. The various chemical "matrices" in which a substance must be measured in these fields require some form of chemical sample preparation before the instrumental measurement. This sample preparation is an unavoidable part of the total measurement procedure (see entry 2.6 in [1]). Therefore, the uncertainty associated with this chemical operation, automatically becomes a component of the final measurement uncertainty of the measurement result. The frequent omission of this component may be one (possible) reason for the fact that so many measurement results for the same measurand in the same material matrix do not seem to be equivalent: the stated measurement uncertainties are too small.

A fourth feature was the introduction of the "intention" of the analyst when measuring, reflected in the basic redefinition of the concept 'measurand': quantity intended to be measured. A consequence of this definition is that the analyst must think clearly about what (s)he is going to measure (and announce that in the beginning of any subsequent publication of the ensuing measurement result).

A fifth feature of VIM 3 is the definition of 'metrology' as "science of measurement and its application" stating explicitly that "metrology includes all theoretical and practical aspects of measurement whatever the measurement uncertainty and field of application". The VIM therefore is applicable from a measurement of time (with $10^{-13}$ relative measurement uncertainty or less) to the measurement of ultra-low trace levels of dioxin in chicken where a relative measurement uncertainty of $100 \%$ would be fully appropriate for the intended use of the measurement result.

Last but not least, a sixth feature of VIM 3, is fulfilling the need for common concepts and associated terms

- for future ISO Guides and Standards,

- for any future SI brochure [8],

- for future Directives and Regulations in legal frameworks,
- for future legal texts involving OIML,

- for future WTO (World Trade Organization) settlement of disputes,

- for CIPM-MRAs (Multilateral Recognition Arrangements)

- for ILAC-MLAs (Multi-lateral Arrangements),

- for description of (old and new) quantities, and

- for re-definitions of units.

The ISO Technical Management Board (TMB) decided some years ago (2001) to install a (renewed) Technical Advisory Group "ISO-TAG 4" and requested it to draft scope and objectives of its work by 2002. The TAG 4 formulated these as follows:

"to promote and coordinate the use of Guide to the Expression of Uncertainty in Measurement (GUM) and International Vocabulary of Basic and General Terms in Metrology (VIM) in the work of TAGs, TCs and their SCs, and other ISO bodies involved in or affected by metrology and metrology-related activities".

The 2012 VIM is an essential tool to arrive at a common language on measurement results on the intercontinental scene for use in the above described contexts.

\section{References}

1. BIPM, IEC, IFCC, ILAC, IUPAC, IUPAP, ISO, OIML (2012) The international vocabulary of metrology — basic and general concepts and associated terms (VIM), 3rd edn. JCGM 200:2012. http:// www.bipm.org/vim

2. BIPM, IEC, IFCC, ILAC, IUPAC, IUPAP, ISO, OIML (2008) Evaluation of measurement data-guide for the expression of uncertainty in measurement. JCGM 100:2008. http://www.bipm. org/en/publications/guides/gum.html

3. BIPM, IEC, ISO, OIML (1984) International vocabulary of basic and general terms, international organization for standardization. ISO, Geneva

4. BIPM, IEC, IFCC, ISO, IUPAC, IUPAP, OIML (1993/1995) International vocabulary of basic and general terms, international organization for standardization. ISO, Geneva

5. De Bièvre $P$ (2011) Looking back at two decades of "Metrology in Chemistry". Accred Qual Assur 16:591-596

6. Assignment of experimental uncertainties recommendation from a working group, INC 1, to the CIPM (1980), published March 1981, revised August 1981

7. Ehrlich C, Dybkaer R, Wöger W (2007) Evolution of philosophy and description of measurement (preliminary rationale for VIM 3). Accred Qual Assur 12:201-218

8. SI, Le Système International d'Unités-The International System of Units, 8th edn. BIPM 2008, ISBN 92-822-2213-6: http://www. bipm.org/en/si/. Accessed 31 Oct 2011 